\title{
Meta-analysis of dry cow management for dairy cattle. Part 2. Cure of existing intramammary infections
}

\author{
T. Halasa, ${ }^{* 1}$ M. Nielen, ${ }^{*}$ A. C. Whist, $†$ and O. Østerås \\ *Utrecht University, Department of Farm Animal Health and Reproduction, PO Box 80151, 3584 CN Utrecht, the Netherlands \\ †TINE Norwegian Dairies, Department of Norwegian Cattle Health Services, PO Box 58, N-1431 Ås, Norway \\ $\ddagger$ Norwegian School of Veterinary Science, Department of Production Animal Clinical Sciences, PO Box 8146 Dep., N-0033 Oslo, Norway
}

\section{ABSTRACT}

The main goal of dry cow therapy (DCT) is to cure existing intramammary infections (IMI) at dry off. Although several published studies have estimated the cure rate of IMI after DCT, variation among studies is great, which makes it difficult to conduct a proper economic evaluation of DCT. The objective of the present meta-analysis of existing peer-reviewed literature was to provide a summary quantification of quarter IMI cure based on DCT. A meta-analysis relative risk (RR) was calculated per intervention and pathogen group when at least 4 studies were available for analysis per comparison from the 22 selected studies, according to the selection criteria. Results of the meta-analysis were examined using publication bias tests. Blanket DCT with a $95 \%$ confidence interval (CI) provided a 1.78 (1.51 to 2.10) times higher calculated cure rate from quarter IMI during the dry period up to $21 \mathrm{~d}$ postcalving, compared with no DCT. The RR of cure was similar when treatment was conducted for Streptococcus spp. IMI quarters compared with Staphylococcus spp. IMI quarters. The pooled RR with the $95 \%$ CI were 1.83 (1.48 to 2.35 ) and 1.65 (1.38 to 1.96 ), respectively. There was no significant difference between cloxacillin and other DCT products in the cure of quarter IMI during the dry period up to $21 \mathrm{~d}$ postcalving. The pooled RR with the 95\% CI was 1.00 (0.92 to 1.09). Similarly, there was no significant difference between cloxacillin and other DCT products in the cure of quarter Staphylococcus spp. IMI. The pooled RR with the $95 \%$ CI was 1.00 (0.96 to 1.06). The pooled RR with the $95 \%$ CI of quarter IMI cure using selective DCT, compared with no DCT, was 1.76 (1.23 to 2.54).

Key words: mastitis, dairy cattle, management, dry period

\footnotetext{
Received September 23, 2008.

Accepted March 31, 2009.

${ }^{1}$ Corresponding author: t.h.halasa@uu.nl
}

\section{INTRODUCTION}

There are 2 main objectives of dry cow therapy (DCT): eliminating existing IMI present at drying off and preventing new IMI during the dry period (DP) and around calving. Pearson $(1950,1951)$ published some of the first papers on DCT in response to great concerns about summer mastitis in nonlactating or dry heifers and cows. However, since then scientists have sought more evidence for the efficacy of DCT. In 1962, Oliver et al. (1962) commenced an experimental DCT trial based on which they concluded that Staphylococcus aureus IMI during the DP is primarily due to pathogens that contaminate the teats after the last milking of the lactation. They also concluded that infusion of antibiotics at the beginning of the DP could provide nearly full protection against infection with Staphylococcus spp. and Streptococcus spp. (Oliver et al., 1962).

During the 1960s and 1970s, the reports by Oliver et al. (1956a,b,c,d,e,f, 1962) were often cited, and blanket DCT (BDCT) was recommended as an important tool to reduce the level of IMI during the beginning of the DP (Kingwill et al., 1970). However, Oliver and Mitchell (1983) noted that these studies were performed under conditions markedly different from those in current dairy systems (that is, $20 \mathrm{yr}$ after the studies in question). Because trial results from the 1960s and 1970s were limited and generally evaluated the efficacy of antibiotics intended for lactation treatment, additional investigations into DCT were needed (Oliver and Mitchell, 1983). A major development was the formulation of DCT products that could achieve slow release over the DP and around calving (Pankey et al., 1982a,b). Rindsig et al. (1978) completed a trial comparing BDCT and selective DCT (SDCT), based on which they concluded that SDCT was as effective as $\mathrm{BDCT}$ in eliminating existing infections, but that BDCT should be preferred in situations in which there would be concern for new infections during the DP.

Frequently, studies investigated the efficacy of quarter IMI cure by comparing different DCT products (Pankey et al., 1982b; Davidson et al., 1994). Cloxacil- 
lin was frequently challenged because of its common use as a DCT application (Ziv et al., 1981; Dingwell et al., 2003).

In the various efficacy trials, great variation among studies was observed, which could have been due to different study designs and the application of different DCT products (Erskine et al., 2003). Surprisingly, a systematic review of all estimates was not published, and this is essential for treatment decisions and economic evaluation of DCT applications. The objective of the present meta-analysis study was to provide a summary quantification of quarter IMI cure using different DCT management strategies based on existing peer-reviewed literature.

\section{MATERIALS AND METHODS}

\section{Selection of Papers}

A search was conducted of literature related to DP management published between 1930 and the beginning of 2008. The search was carried out using different key words in PubMed (National Library of Medicine, Bethesda, MD) and the reference citation procedure in the ISI Web of Knowledge (Thompson Reuters Corporation, Philadelphia, PA).

Papers to be included in the meta-analysis had to 1) be original research papers published in a peer-reviewed journal; 2) report the number or the rate of IMI cure at the quarter level in at least 2 groups (treatment and control group) and the total number of infected quarters in each group; 3) be published in or have a summary in English; and 4) report the outcome of a new data set or protocol. (When several studies were published based on the same data, the most detailed study was used.) Furthermore, only protocols that involved a therapeutic dose that was high enough (as recommended by the original studies) were included. Protocols with subtherapeutic doses were not included, in order not to bias the weighted averages of the cure rate. Further details per study were considered based on the interventions involved and are explained in the next section.

A total of 23 studies fit the criteria, 22 of which were included in the meta-analysis. One study (Newbould, 1979) was excluded because of serious design differences compared with the other studies. The studies report the outcomes of one or of several protocols. When several protocols were reported, Roman numerals were added to distinguish among the protocols. Two formats were observed in each type of study selected: treatments were applied either to the cow or to a single quarter. Table 1 and the descriptive results show data related to the study design and the level of analysis per study.

\section{Management Groups Involved in the Meta-Analysis}

Studies that reported the number or rate of quarter IMI cure during the DP up to $21 \mathrm{~d}$ postcalving using BDCT were included in the analysis. In these studies, the treatment group was treated IMI quarters at dry off, whereas the control group was untreated IMI quarters at dry off. A separate analysis was also conducted on studies reporting the cure rate during the DP using cloxacillin as the treatment group and the other DCT preparation as the control group.

Studies that measured the number or rate of quarter IMI cure using SDCT during the DP up to $21 \mathrm{~d}$ postcalving were included in the analysis. Selection of treatment unit was at either the quarter or the cow level. However, the analysis could not be carried out separately per selection unit for treatment, because there was only one study (Østerås et al., 1994) in which quarter was the selection unit for treatment. This would have led to potential misestimation of the summary estimate.

\section{Definition of a Cure}

The definition of cure considered 2 possibilities. First, a quarter was considered cured when a pathogen was not isolated at calving or postcalving from a quarter that had had an isolate of a pathogen at drying off. This was the definition most frequently used. Second, when a pathogen was isolated in the postcalving sample from a quarter that had had a different isolate at dry off, it was considered that the quarter was cured of the first pathogen and that a new IMI had been acquired. This was rarely encountered, and the number of such quarters had not been mentioned in the original studies.

\section{Recalculating the Incidence of Cure}

The definition of cure (see previous section) included quarters in which a pathogen had been isolated at drying off that had become bacteriologically negative or quarters that had a different pathogen in the calving or postcalving sampling. Thus, the cumulative incidence of cure, which is called the "cure rate" throughout this paper, was recalculated as the number of cured quarters divided by the total number of IMI quarters at dry off. The IMI quarters were assumed to be the total number of quarters at risk for cure during the DP up to $21 \mathrm{~d}$ postcalving.

\section{Meta-Analysis Procedure}

Outcome Parameters. The relative risk (RR) of cure (cure rate in the treatment group divided by 
Table 1. Description of each study included in the meta-analysis ranked in alphabetical order

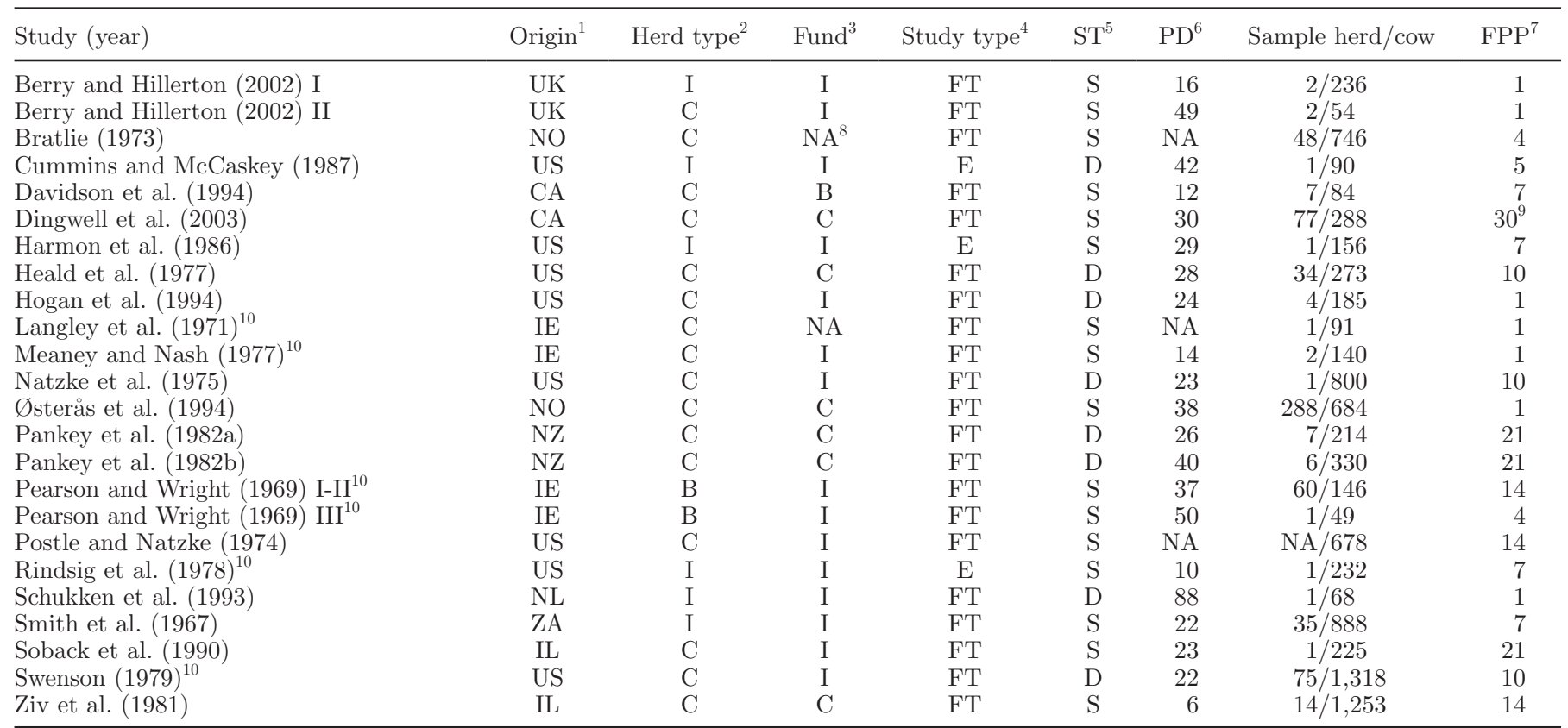

${ }^{1} \mathrm{UK}=$ United Kingdom; NO = Norway; US = United States; CA = Canada; IE = Ireland; NZ = New Zealand; NL = the Netherlands; ZA = South Africa; IL = Israel.

${ }^{2}$ Type of herds where the study was conducted: institutional and research herds (I), commercial (C), or both herds (B).

${ }^{3}$ Source of funding: institutional and governmental (I), commercial (C), or both (B).

${ }^{4}$ Study type: field trial (FT) or experiment (E).

${ }^{5}$ Samples type used to confirm diagnosis: single (S) or double (D).

${ }^{6}$ Prevalence (\%) at dry off.

${ }^{7}$ Follow-up period postcalving in days.

${ }^{8} \mathrm{NA}=$ not available.

${ }^{9}$ Three consecutive samples were taken postcalving only to confirm cure during the dry period.

${ }^{10} \mathrm{~A}$ within-cow comparison was conducted, whereas other studies conducted a between-cow comparison.

the cure rate in the control group) was calculated per study, and then RR per intervention were pooled in a meta-analysis by using a commercial product (Comprehensive Meta Analysis, 2008). The pooled RR are presented per intervention as an overall effect (all pathogens together), and per pathogen group (Staphylococcus spp., and Streptococcus spp.) separately. In studies that included more than one protocol, a combined effect was calculated per study (Comprehensive Meta Analysis, 2008).

Meta-regression was not conducted because of the small sample size per subgroup on variables, as presented in Table 1 . The small number of studies per subgroup might indicate a lack of difference between the subgroups because of a lack of power and not because of a lack of difference. Therefore, a random effect model was used to calculate the pooled RR (Comprehensive Meta Analysis, 2008). The pooled RR are presented with its $95 \%$ confidence interval (CI) and its $95 \%$ prediction interval (PI). The PI was calculated based on Chebyshev's inequality, which indicates that at least
$95 \%$ of the true effects would lie within 4.47 standard deviations of the mean effect (Higgins et al., 2009). The PI indicates the limits within which the estimate of a future trial would exist (Higgins et al., 2009). The weighted average of cure was calculated by multiplying the estimated cure rate per study by the weight assigned to each study and was summed over all studies and then divided by the sum of the weights. The corresponding $95 \%$ CI was calculated based on the cure rates in the original studies.

Publication Bias. The publication bias was assessed by using the fill and trim method of Duval and Tweedie (2000), the rank correlation test of Begg and Mazumdar (1994), and the regression test of Egger et al. (1997). When significant publication bias and change in the estimated pooled RR was detected, the number of studies necessary to reverse the overall pooled effect was calculated using the fail-safe $\mathrm{N}$ method of Orwin (1983). The influence of study was also examined by using the one study removed method (Dohoo et al., 2003). When significant publication bias was deemed to exist, 
the pooled $\mathrm{RR}$ was presented based on the fill and trim method estimation of Duval and Tweedie (2000) after correcting for the bias.

\section{RESULTS}

\section{Descriptive Results}

Herds, Cows, and Funding. Fifteen studies were conducted in commercial herds, 5 were conducted in institutional or research herds, and 2 were conducted in both research and commercial herds (Table 1). Although the number of herds varied from 1 herd, mainly in experimental studies, to 288 herds, in field trials, the number of cows varied from 68 cows to 1,318 in field trials (Table 1). The funding was obtained from institutional and governmental funds for 13 studies, from commercial funds for 6 studies, and from both institutional and commercial funds for 1 study, and in 2 studies, the source of funding was unknown (Table 1).

Experimental Design. All studies involved were randomized field trials (19 studies), and 3 were experimental studies (Table 1). Although the inclusion criteria varied among studies, frequently the infection status at dry off was used as the criterion to include cows. Most studies had a negative control group, except for studies comparing cloxacillin with other DCT products. In general, most studies were based on between-cow comparisons (see footnote for column 1 in Table 1).

Milk Samples for Bacterial Culturing. In all studies, milk samples were collected at dry off, and at calving or up to $21 \mathrm{~d}$ postcalving (Table 1 ). The dry-off sample was used to confirm the existence of quarter IMI, whereas the sample taken at calving or postcalving was used to diagnose the cure of quarter IMI. In 14 studies, single consecutive samples were collect to diagnose IMI, whereas in the other studies, a duplicate sample (at 1 point in time) was collected (Table 1 ).

Bacteriological Culturing Procedure. The procedure of the National Mastitis Council was the procedure followed in most studies (Hogan et al., 1999). Other studies used modified procedures based on the National Mastitis Council procedures. Nevertheless, in all studies the handling of samples, from farm to processing, was similar, especially storage, freezing, and processing. Milk samples were obtained by proper cleaning of the teat and after discarding the first 3 to 4 squirts of milk. In most studies, samples were stored at $-20^{\circ} \mathrm{C}$ until processed.

\section{Management Application}

BDCT vs. No DCT ( $n=14$ Studies $)$. The treatment was based on intramammary injection of the antibiotics tested, in all quarters and all studies except in the study by Soback et al. (1990), in which systemic DCT was applied intramuscularly.

Cloxacillin vs. Other DCT Products $(n=6$ Studies). In all studies, cloxacillin and the other product were applied by the intramammary route.

SDCT vs. No DCT ( $n=4$ Studies). Treatment was carried out based on the unit of selection. At the cow level, when one or more quarters had IMI, each quarter of the whole udder was injected with the antibiotics being tested (Bratlie, 1973; Rindsig et al., 1978; Berry and Hillerton, 2002). At the quarter level, only quarters that had IMI were injected with the tested antibiotics (Østerås et al., 1994). Other quarters within the same udder were left untreated. In the control group, no DCT was given to IMI quarters.

\section{Meta-Analysis Results}

$B D C T$ vs. No DCT. In general, the cure rate after DCT (with 95\% CI in parentheses) was on average $78 \%$ (71 to $85 \%$ ), whereas the spontaneous cure rate was on average $46 \%$ (37 to $56 \%$ ). Quarters with IMI that had had DCT had a cure rate 1.78 times $(95 \% \mathrm{CI}=1.51$ to 2.10) higher during the DP and early lactation than did untreated IMI quarters. The $95 \%$ PI was 1.15 to 2.42 (Table 2). The RR was not altered by removing any of the studies, and none of the publication bias tests indicated the presence of significant bias.

On average, cure rate from Staphylococcus spp. IMI after DCT (with 95\% CI in parentheses) was 77\% (68 to $86 \%$ ), whereas the spontaneous cure was on average $44 \%$ (32 to 56\%). Dry cow therapy led to a 1.65 times higher calculated cure from Staphylococcus spp. IMI compared with no DCT (Table 2). All publication bias tests indicated an absence of significant bias (results not shown).

On average, DCT (with 95\% CI in parentheses) led to an $89 \%$ (83 to $95 \%$ ) cure rate from Streptococcus spp. IMI, whereas the spontaneous cure of Streptococcus spp. IMI was $47 \%$ (33 to $61 \%$ ). The pooled RR was 1.86 and the $95 \%$ CI was 1.48 to 2.35 . No significant publication bias was identified by any of the publication bias tests.

Cloxacillin vs. Other DCT Products. There was no significant difference in the cure rate of IMI when cloxacillin was compared with other DCT products (Table 2). No bias was identified by any of the publication bias tests (results not shown).

When the cure from Staphylococcus spp. IMI using cloxacillin was compared with the cure using other DCT products, cloxacillin showed a cure rate similar to the other DCT products (Table 2). The effect was not altered by removing any of the studies (results not 


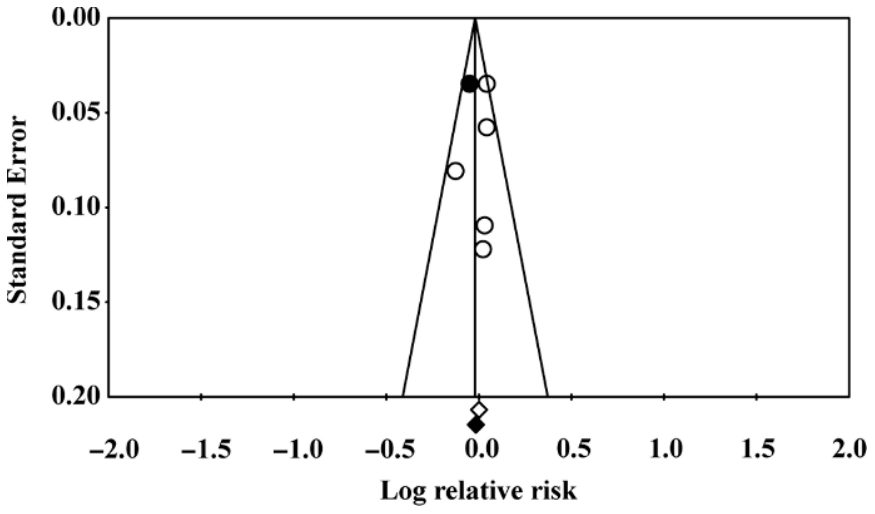

Figure 1. Funnel plot of studies involved in the estimation of the relative risk $(\mathrm{RR})$ of cure from quarter Staphylococcus $\mathrm{spp}$. IMI. $\mathrm{RR}=$ cure rate of quarter Staphylococcus spp. IMI using cloxacillin divided by the cure rate using other blanket dry cow therapy products during the dry period together with the missing study (solid circle) as identified using the fill and trim method of Duval and Tweedie (2000) for the 5 studies included (open circles). The open and solid diamonds indicate the $\log \mathrm{RR}$ and its $95 \%$ confidence interval before and after including the effect of the missed study, respectively.

shown). The rank correlation test of Begg and Mazumdar (1994) showed that there was no significant correlation between effect and study size $(P=0.14)$. This was also confirmed by the regression test of Egger et al. (1997), which showed no significant association between study size and effect (intercept $=-0.89$ with 3 df; $P=0.22$ ). The fill and trim method of Duval and Tweedie (2000) suggested that there was a missing study on the right-hand side of the funnel plot to reach complete symmetry (Figure 1). Adding this study did not alter the effect significantly.

SDCT vs. No $\boldsymbol{D C T}$. On average, the cure rate in the SDCT group (with 95\% CI in parentheses) was $83 \%$ (73 to $93 \%$ ), and spontaneous cure was on average $52 \%$ (33 to $71 \%$ ). Selective DCT provides a higher cure rate of IMI compared with no DCT (Table 2). Treated IMI quarters at dry off had a $1.76(95 \%$ CI $=$ 1.23 to 2.54 ) times higher cure rate during the DP and early lactation than did untreated quarters (Table 2). The analysis was not carried out per pathogen group because the number of studies was fewer than 4. All publication bias tests suggested an absence of bias.

\section{DISCUSSION}

The RR of cure from Staphylococcus spp. IMI was not significantly different from that for the Streptococcus spp. IMI because the CI overlapped. This could be explained by species differences in the cure within a pathogen group, leading to a similar pooled cure rate between pathogen groups. For instance, Heald et al. (1977) found that the cure of IMI quarters was higher for Streptococcus spp. other than Strep. agalactiae compared with the cure rate from Staph. aureus IMI, but when the cure from Strep. agalactiae IMI was pooled with the other Streptococcus spp. and compared with

Table 2. Pooled relative risk $\left(\mathrm{RR}^{1}\right)$ of cure from quarter IMI during the dry period up to $21 \mathrm{~d}$ postcalving, together with the $95 \%$ confidence interval (CI) and the $95 \%$ predictive interval (PI) beneath the pooled RR and the studies involved in each meta-analysis per intervention comparison for all pathogens together (overall), Staphylococcus spp., and Streptococcus spp. ${ }^{2}$

\begin{tabular}{|c|c|c|}
\hline Intervention & Studies included in each meta-analysis & $\begin{array}{l}\mathrm{RR}(95 \% \mathrm{CI}) \\
\quad(95 \% \mathrm{PI})\end{array}$ \\
\hline \multicolumn{3}{|l|}{ BDCT vs. no DCT } \\
\hline Staphylococcus spp. & $\begin{array}{l}\text { Cummins and McCaskey (1987); Harmon et al. (1986); Heald et al. (1977); } \\
\text { Hogan et al. (1994); Langley et al. (1971); Natzke et al. (1975); Pankey et al. (1982a,b); } \\
\text { Pearson and Wright (1969); Postle and Natzke (1974); Schukken et al. (1993); } \\
\text { Smith et al. (1967); Soback et al. (1990); Swenson (1979) }\end{array}$ & $\begin{array}{l}1.65(1.38 \text { to } 1.96) ; \\
\quad(1.01 \text { to } 2.25)\end{array}$ \\
\hline Streptococcus spp. & $\begin{array}{l}\text { Cummins and McCaskey (1987); Heald et al. (1977); Hogan et al. (1994); Natzke et al. (1975); } \\
\text { Pankey et al. (1982b); Pearson and Wright (1969); Postle and Natzke (1974); } \\
\text { Schukken et al. (1993); Smith et al. (1967); Swenson (1979) }\end{array}$ & $\begin{array}{l}1.86(1.48 \text { to } 2.35) ; \\
\quad(1.15 \text { to } 2.57)\end{array}$ \\
\hline \multicolumn{3}{|c|}{ Cloxacillin vs. other DCT } \\
\hline Overall & $\begin{array}{l}\text { Davidson et al. (1994); Dingwell et al. (2003); Langley et al. (1971); Meaney and Nash (1977); } \\
\text { Pankey et al. (1982b); Ziv et al. (1981) }\end{array}$ & $\begin{array}{l}1.00(0.92 \text { to } 1.09) \\
\quad(0.77 \text { to } 1.17)\end{array}$ \\
\hline
\end{tabular}

${ }^{1}$ Cure rate of IMI using dry cow therapy (DCT) divided by the cure rate in the untreated IMI quarters. RR $>1$, increased cure rate; $\mathrm{RR}=1$, no cure; $\mathrm{RR}<1$, decreased cure rate.

${ }^{2}$ Interventions were blanket dry cow therapy (BDCT), cloxacillin vs. other dry cow therapy (DCT) products, and selective DCT (SDCT). 
the cure rate from Staph. aureus IMI, no difference in the cure rate of IMI was observed between the Streptococcus spp. and Staph. aureus. Another explanation could be the vast array of therapies and doses used in the different studies; the diversity among studies would limit the comparison between pathogen groups. This could also have been the reason nonsignificant differences were found between cloxacillin and other DCT products (Table 2).

Selective DCT showed a similar RR of cure compared with BDCT (Table 2). In a recent field trial, cows were selected for SDCT based on their SCC in the month before drying off (Whist et al., 2007). The cure rate at the population level increased when high-SCC cows $(>400,000$ cells $/ \mathrm{mL})$ were not included for SDCT analysis (Whist et al., 2007). This indicates that the prognosis of treatment could be highly dependent on cow factors (Østerås et al., 1999).

The current study provided the PI around the estimated pooled RR. Traditionally, the CI indicates the uncertainty around the mean effect estimation, where this uncertainty is reduced by additional observations, leading to a narrow $95 \%$ CI. For economic analysis, the true population variation is important because economic analysis should be comprehensive and should represent extreme situations (Halasa et al., 2007). Thus, the PI, which is empirically wider, may be better than the CI to represent the range of situations when distributions are selected or sensitivity analysis is conducted in economic models.

The way the PI was calculated in the current paper was based on a basic but valid approach (Higgins et al., 2009). Another approach suggested is using Bayesian analysis, which can predict an $\mathrm{RR}$ value for a new study with its PI (Higgins et al., 2009). However, this approach is more complicated and our meta-analysis software did not support this approach.

\section{Overall Discussion of Management to Prevent and Cure IMI During the DP Up to $21 d$ Postcalving, Related to Parts 1 and 2}

Because DCT aims to cure existing IMI and prevent new IMI during the DP and around calving, the current study and the companion paper (Halasa et al., 2009) summarized these 2 important aspects based on the peer-reviewed research published in English. The current study revealed that DCT provided a high cure rate of Staphylococcus spp. and Streptococcus spp. IMI at dry off. Significant publication bias was not detected. The companion study (Halasa et al., 2009) showed that DCT provided significant protection against new Streptococcus spp. quarter IMI. However, protection was doubtful against new Staphylococcus spp. quarter IMI after correcting for publication bias. With DCT, the cure rates against Staphylococcus spp. IMI were high in most studies, which made it easy to achieve their publication because the results reached significant levels even in small studies (Dohoo et al., 2003). However, again using DCT, because the rate of prevention of new Staphylococcus spp. IMI is not as great as the cure rate, we expected that studies measuring new Staphylococcus spp. IMI would not show significant effects, and consequently would not succeed in being published. These studies appeared to be missing from the meta-analysis (see the discussion section of Halasa et al., 2009). This could explain the absence of certain studies for Staphylococcus spp. in the companion paper (Halasa et al., 2009), but not in the current one.

On the basis of our 2 meta-analytical studies, it can be concluded that DCT is effective in curing and protecting against new quarter IMI during the DP up to $21 \mathrm{~d}$ postcalving (Halasa et al., 2009), although this depends on the pathogen causing the IMI. However, internal teat sealant showed good potential to protect against new IMI. Therefore, the combination of DCT and internal teat sealant might be a good control procedure on some farms because DCT would cure existing IMI at dry off and teat sealant would prevent new IMI during the DP; see the companion paper for detailed information about the effect of teat sealant in preventing new IMI during the DP (Halasa et al., 2009). However, such a recommendation should be supported by field data and, thereafter, by proper calculations of their economic importance.

The 2 meta-analytical studies provided an important observation in relation to SDCT. When the cow was the selection unit for treatment, SDCT provided protection against new IMI as well as did BDCT, and it showed similar efficacy in curing existing IMI. This might make SDCT based at the cow level a good choice to optimize production and might limit the use of antibiotics. However, the data were limited and more studies on SDCT at the cow and quarter levels might be helpful to confirm or reject this important observation. Moreover, such a recommendation should be supported by an economic analysis that takes into account field situations.

\section{CONCLUSIONS}

Blanket DCT provided a 1.78 times higher calculated cure rate from quarter IMI compared with no DCT, and this was similar for SDCT, at 1.76. The RR of cure for BDCT was not significantly different when treatment was conducted for Streptococcus spp. IMI quarters compared with Staphylococcus spp. IMI quarters.

There was no significant difference between cloxacillin and other DCT products in curing quarter IMI from all 
pathogens, and specifically from quarter Staphylococcus spp. IMI, during the DP up to $21 \mathrm{~d}$ postcalving. The estimated cure rates can be used in further economic analyses.

\section{ACKNOWLEDGMENTS}

The authors acknowledge the Norwegian School of Veterinary Science for financial support.

\section{REFERENCES}

Begg, C. B., and M. Mazumdar. 1994. Operating characteristics of a rank correlation test for publication bias. Biometrics 50:10881101.

Berry, E. A., and J. E. Hillerton. 2002. The effect of selective dry cow treatment on new intramammary infections. J. Dairy Sci. 85:112-121.

Bratlie, O. 1973. Dry cow therapy. Vet. Rec. 93:430-431.

Comprehensive Meta Analysis. 2008. Meta-Analysis Manual. Biostat Inst. Inc., Englewood Cliffs, NJ.

Cummins, K. A., and T. A. McCaskey. 1987. Multiple infusions of cloxacillin for treatment of mastitis during the dry period. J. Dairy Sci. 70:2658-2665.

Davidson, T. J., I. R. Dohoo, and A. W. Donald. 1994. Comparing two dry cow treatments on the new infection and elimination rates of coagulase-negative staphylococci. Can. Vet. J. 35:775-776.

Dingwell, R. T., K. E. Leslie, T. F. Duffield, Y. H. Schukken, L. Des Coteaux, G. P. Keefe, D. F. Kelton, K. D. Lissemore, W. Shwefelt, P. Dick, and R. Bagg. 2003. Efficacy of intramammary tilmicosin and risk factors for cure of Staphylococcus aureus infection in the dry period. J. Dairy Sci. 86:159-168.

Dohoo, I. R., S. W. Martin, and H. Stryhn. 2003. Veterinary Epidemiological Research. Atlantic Vet. Coll. Inc., Charlottetown, Prince Edward Island, Canada.

Duval, S., and R. Tweedie. 2000. A non-parametric "trim and fill" method of accounting for publication bias in meta-analysis. J. Am. Stat. Assoc. 95:89-98.

Egger, M., G. Davey Smith, M. Schneider, and C. Minder. 1997. Bias in meta-analysis detected by a simple graphical test. BMJ 315:629-634.

Erskine, R., S. Wagner, and F. De Graves. 2003. Mastitis therapy and pharmacology. Vet. Clin. Food Anim. 19:109-138.

Halasa, T., K. Huijps, O. Østerås, and H. Hogeveen. 2007. Economic effects of bovine mastitis and mastitis management: A review. Vet. Q. 29:18-31.

Halasa, T., M. Nielen, T. Van Werven, H. Hogeveen, and O. Østerås. 2009. Meta-analysis of dry cow management for dairy cattle. Part 1. Protection against new intramammary infections. J. Dairy Sci. 92:3134-3149.

Harmon, R. J., W. L. Crist, R. W. Hemken, and B. E. Langlois. 1986. Prevalence of minor udder pathogens after intramammary dry treatment. J. Dairy Sci. 69:843-849.

Heald, C. W., G. M. Jones, S. Nickerson, and T. L. Bibb. 1977. Mastitis control by penicillin and novobiocin at drying-off. Can. Vet. J. 18:171-180.

Higgins, J. P. T., S. G. Thompson, and D. J. Spiegelhalter. 2009. A re-evaluation of random-effects meta-analysis. J. R. Stat. Soc. Ser. A, Stat. Soc. 172:137-159.

Hogan, J. S., R. N. Gonzales, R. J. Harmon, S. C. Nickerson, S. P. Oliver, J. W. Pankey, and K. L. Smith. 1999. Laboratory Handbook on Bovine Mastitis. Natl. Mastitis Counc., Madison WI.

Hogan, J. S., K. L. Smith, D. A. Todhunter, and P. S. Schoenberger. 1994. Efficacy of dry cow therapy and a Propionibacterum acnes product in herds with low somatic cell count. J. Dairy Sci. $77: 3331-3337$.
Kingwill, R. G., F. K. Neave, F. H. Dodd, T. K. Griffin, and D. R. Westgarth. 1970. The effect of a mastitis control system on levels of subclinical and clinical mastitis in two years. Vet. Rec. $87: 94-100$.

Langley, O. H., J. Meaney, N. P. Cullen, and F. Cunningham. 1971. The control of mastitis. Vet. Rec. 89:315-316.

Meaney, W. J., and J. M. Nash. 1977. Comparison of two dry cow intramammary treatments. Vet. Rec. 100:492-493.

Natzke, R. P., R. W. Everett, and D. R. Bray. 1975. Effect of drying off practices on mastitis infection. J. Dairy Sci. 58:1828-1835.

Newbould, F. S. H. 1979. The use of induced mammary infections for evaluating dry cow treatment products. II. Trial of a proposed method to compare three levels of Novobiocin. Can. J. Comp. Med. 43:430-433.

Oliver, J., F. H. Dodd, and F. K. Neave. 1956a. Infection and mastitis in a dairy herd 1945-53. J. Dairy Res. 23:169-180.

Oliver, J., F. H. Dodd, and F. K. Neave. 1956b. Udder infection in the "dry period." III. The method of drying-off cows at the end of lactation. J. Dairy Res. 23:197-203.

Oliver, J., F. H. Dodd, and F. K. Neave. 1956c. Udder infection in the "dry period" IV. The relationship between the new infection rate in the early dry period and the daily milk yield at drying-off when lactation was ended by either intermittent or abrupt cessation of milking. J. Dairy Res. 23:204-211.

Oliver, J., F. H. Dodd, and F. K. Neave. 1956d. Udder infection in the "dry period. V. The effect of teat disinfection at drying-off on the incidence of infections in the early dry period. J. Dairy Res. $23: 212-216$.

Oliver, J., F. H. Dodd, F. K. Neave, and G. L. Bailiy. 1956e. Variations in the incidence of udder infection and mastitis with stage in lactation, age and season of the year. J. Dairy Res. 23:181-193.

Oliver, J., F. H. Dodd, F. K. Neave, and J. M. Lee. 1956f. Udder infection in the "dry period." II. The effect of withdrawing secretion from the dry udder on the incidence of infection. J. Dairy Res. 23:194-196.

Oliver, J., F. Neave, and E. Sharpe. 1962. The prevention of infection of the dry udder. J. Dairy Res. 29:95-100.

Oliver, S. P., and B. A. Mitchell. 1983. Susceptibility of bovine mammary gland to infections during the dry period. J. Dairy Sci. 66:1162-1166.

Orwin, R. 1983. A fail-safe $\mathrm{N}$ for effect size in meta-analysis. J. Educ. Stat. 8:157-159.

Østerås, O., J. Aursjo, G. Gronningsaeter Gjul, and A. Jorstad. 1994. Effect of dry-cow therapy on subclinical mastitis-An evaluation of long acting and short acting intramammaria. J. Vet. Med. B 41:529-540.

Østerås, O., V. L. Edge, and S. W. Martin. 1999. Determinants of success or failure in the elimination of major mastitis pathogens in selective dry cow therapy. J. Dairy Sci. 82:1221-1231.

Pankey, J. W., R. M. Barker, A. Twomey, and G. Duirs. 1982a. Comparative efficacy of dry-cow treatment regimens against Staphylococcus aureus. N. Z. Vet. J. 30:13-15.

Pankey, J. W., R. M. Barker, A. Twomey, and G. Duirs. 1982b. A note on effectiveness of dry cow therapy in New Zealand dairy herds. N. Z. Vet. J. 30:50-52.

Pearson, J. K. L. 1950. The use of penicillin in the prevention of $C$. pyogenes infection of the non-lactating udder. Vet. Rec. 62:166168.

Pearson, J. K. L. 1951. Further experiments in the use of penicillin in the prevention of $C$. pyogenes infection of the non-lactating udder. Vet. Rec. 63:215-220.

Pearson, J. K. L., and C. L. Wright. 1969. Dry cow therapy as a means of controlling bovine mastitis. Vet. Rec. 84:294-298.

Postle, D. S., and R. P. Natzke. 1974. Efficacy of antibiotic treatment in the bovine udder as determined from field studies. Vet. Med. Small Anim. Clin. 69:1535-1539.

Rindsig, R. B., R. G. Rodewald, A. R. Smith, and S. L. Spahr. 1978. Complete versus selective dry cow therapy for mastitis control. J. Dairy Sci. 61:1483-1497. 
Schukken, Y. H., J. Van Vliet, D. Van de Geer, and F. J. Grommer. 1993. A randomized blind trial on dry cow antibiotic infusion in a low somatic cell count herd. J. Dairy Sci. 76:2925-2930.

Smith, A., D. R. Westgarth, M. R. Jones, F. K. Neave, F. H. Dodd, and G. C. Brander. 1967. Methods of reducing the incidence of udder infection in dry cows. Vet. Rec. 81:504-510.

Soback, S., G. Ziv, M. Winkler, and A. Saran. 1990. Systemic dry cow therapy-A preliminary report. J. Dairy Sci. 73:661-666.

Swenson, G. H. 1979. Posology and field efficacy study with novobiocin for intramammary infusion in nonlactating dairy cows. Can. J. Comp. Med. 43:440-447.
Whist, A. C., O. Østerås, and L. Sølverød. 2007. Staphylococcus aureus and Streptococcus dysgalactiae in Norwegian herds after introduction of selective dry cow therapy and teat dipping. J. Dairy Res. 74:1-8.

Ziv, G., M. Storper, and A. Saran. 1981. Comparative efficacy of three antibiotic products for the treatment and prevention of subclinical mastitis during the dry period. Vet. Q. 3:74-79. 